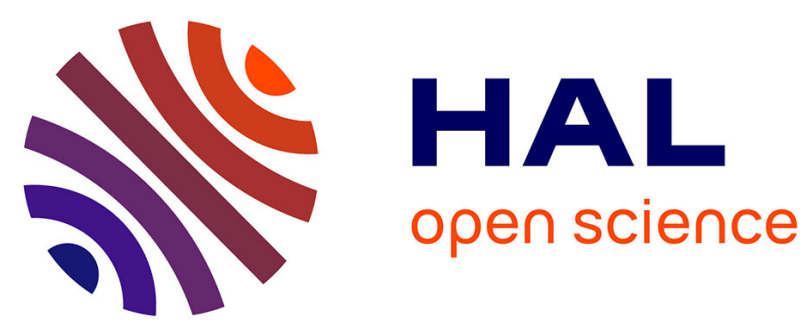

\title{
SEPP1 polymorphisms modulate serum glucose and lipid response to Brazil nut supplementation
}

\author{
Janaina L. S. Donadio, Marcelo M. Rogero, Elvira M. Guerra-Shinohara, \\ Charles Desmarchelier, Patrick Borel, Silvia M. F. Cozzolino
}

\section{To cite this version:}

Janaina L. S. Donadio, Marcelo M. Rogero, Elvira M. Guerra-Shinohara, Charles Desmarchelier, Patrick Borel, et al.. SEPP1 polymorphisms modulate serum glucose and lipid response to Brazil nut supplementation. European Journal of Nutrition, 2017, 57 (5), Epub ahead of print. 10.1007/s00394017-1470-7 . inserm-01531459

HAL Id: inserm-01531459 https://www.hal.inserm.fr/inserm-01531459

Submitted on 8 Apr 2018

HAL is a multi-disciplinary open access archive for the deposit and dissemination of scientific research documents, whether they are published or not. The documents may come from teaching and research institutions in France or abroad, or from public or private research centers.
L'archive ouverte pluridisciplinaire HAL, est destinée au dépôt et à la diffusion de documents scientifiques de niveau recherche, publiés ou non, émanant des établissements d'enseignement et de recherche français ou étrangers, des laboratoires publics ou privés. 
1 SEPP1 polymorphisms modulate serum glucose and lipid response to Brazil nut

\section{2 supplementation}

3

4 Janaina L S Donadio ${ }^{1 *}$, Marcelo M Rogero ${ }^{2}$, Elvira M Guerra-Shinohara ${ }^{3}$, Charles

5 Desmarchelier ${ }^{4}$, Patrick Borel $^{4}$, Silvia M F Cozzolino ${ }^{1}$

6

$7 \quad{ }^{1}$ Department of Food and Experimental Nutrition, Faculty of Pharmaceutical Sciences,

8 University of São Paulo, São Paulo, Brazil

$9 \quad{ }^{2}$ Department of Nutrition, School of Public Health, University of São Paulo, São Paulo, 10 Brazil

$11{ }^{3}$ Department of Clinical and Toxicological Analyses, Faculty of Pharmaceutical 12 Sciences, University of São Paulo, São Paulo, Brazil

$13{ }^{4}$ NORT, Aix-Marseille Université, INRA (French National Institute for Agricultural 14 Research), INSERM, 13005, Marseille, France

15 *: Correspondence: janainadonadio@gmail.com

16

17

\section{Acknowledgments}

The authors are grateful to the Sao Paulo Research Foundation (FAPESP process: 2011/17720-0) for the scholarship and the financial support provided for this study. The authors are also very grateful to all volunteers who took part in this study. J.L.S.D., M.M.R. and S.M.F.C. conceived and designed the study; J.L.S.D. was responsible for generation, collection, assembly, analysis and interpretation of data; J.L.S.D, C. D. and E. M. G. S. performed the statistical analysis. J.L.S.D. wrote the manuscript, P.B., S.M.F.C and M.M.R. revised the manuscript. All authors approved the final version of the manuscript for submission. 


\section{Abstract}

30 Purpose The consumption of Brazil nuts has been associated with benefits to lipid metabolism and reductions in total cholesterol and LDL levels. They are the richest natural source of selenium, which has essential functions in human physiology. Genetic polymorphisms in Selenoprotein P could impair lipid and glucose metabolism. The aim of this work was to verify the influence of polymorphisms in genes for selenoproteins on blood lipid levels after dietary supplementation with Brazil nuts in healthy adults. Methods The study included 130 healthy volunteers selected at the University of São Paulo, Brazil. They were supplemented with one nut a day for eight weeks, followed by eight weeks without intervention. The following analyses were performed: anthropometric measurements, serum fasting glucose, lipid profile, C-reactive protein and plasma MDA levels. The volunteers were genotyped for SNPs rs1050450, rs3811699, rs1800699, rs713041, rs3877899, rs7579, rs34713741, and rs5845 in genes for selenoproteins. Results The concentrations of total cholesterol and fasting glucose levels decreased after eight weeks of supplementation $(p<0.05)$. Glucose levels were modulated by rs3877899 in SEPP1, with significantly lower levels observed for individuals with the GA+AA genotype ( $p=0.025)$. In addition, rs7579 was associated with cholesterol concentrations, which were significantly lower for individuals with the GG genotype $(p=0.053)$. Conclusions Supplementation with one Brazil nut a day for eight weeks reduced total cholesterol and glucose levels. Furthermore, our results suggest that rs3877899 might be associated with glucose concentrations and rs7579

50 with cholesterol concentrations. Therefore, the effect of genetic variations should be considered in future nutritional interventions evaluating the response to Brazil nut supplementation.

53 Key words: Brazil nuts, lipid profile, polymorphisms, nutrigenetics 


\section{Introduction}

The consumption of tree nuts (e.g. peanuts, almonds, hazelnuts, walnuts, Brazil nuts, pistachios, cashews, macadamias) has been associated with decreased risk of cardiovascular disease in human trials [1-4]. The benefits of tree nut consumption are probably associated with their nutritional composition: rich in monounsaturated (MUFA) and polyunsaturated fatty acids (PUFA), magnesium, copper, selenium, vitamin E, folic acid and other bioactive compounds such as phytosterols and phenolic acids $[3,5,6]$. The analysis of two human trials, the Nurse's Health Study (NHS) (female subjects) and The Health Professionals Follow-up Study (HPFS) (male subjects), both performed in the USA, revealed that the intake of tree nuts was associated with lower risk of cardiovascular disease [7]. Comparable results were found in the analysis of the National Health and Nutrition Examination Survey (NHANES) from 2005 to 2010 [3].

There are some mechanisms that could explain the positive effect of tree nuts on cardiovascular health. The most accepted is the lipid-lowering effect, since tree nuts have a high content of PUFA that could explain the reduction of total cholesterol and LDL-c levels, observed for almonds, peanuts, walnuts and pecan nuts [4]. The lipidlowering effect of Brazil nuts has been investigated in several studies. The supplementation of one Brazil nut per day during 18 weeks in obese females reduced cardiovascular risk by increasing HDL-c levels [8]. The increase in HDL-c and the decrease in LDL-c were observed in healthy adults after an ingestion of 4 units of Brazil nuts for 4 weeks [9] and a decrease in total cholesterol and LDL-c was observed in obese female adolescents after the ingestion of 3 to 4 units per day during 16 weeks [10]. Brazil nut supplementation did not affect HDL-c and LDL-c levels in another study with healthy adults after ingestion of 10 units of nuts per day during 2 weeks, 
however it did affect the transfer of cholesteryl esters into HDL pool, which is

80 important to reverse cholesterol transport and its elimination into bile. Overall, the increase of cholesteryl esters into HDL pool after consumption of Brazil nuts can be considered as an antiatherogenic effect [11]. amino acid selenocysteine (Sec), Se is inserted into selenoproteins, which have important functions in the antioxidant system, lipid peroxidation, immune function, brain function, diabetes risk, among others [13]. The insertion of Sec into selenoproteins occurs during translation and it requires the presence of a specific structure in the 3'untranslated region (3’UTR) of the mRNA, a specific RNA for Sec ( $\operatorname{tRNA}^{[\mathrm{Ser}] \mathrm{Sec}}$ ), and other structures [14].

In contrast to other selenoproteins, Selenoprotein P (SePP) has ten Sec residues, which are expressed primarily in liver but also in other tissues such as brain, gut, heart, and kidneys [15]. In Se-deficient conditions, SePP is preferentially directed to the brain and testis, which implies the presence of SePP receptors APOER2 in these two tissues

94 [15]. Plasma Se and SePP concentrations are the most used biomarkers of Se status. 95 SePP concentration and mRNA expression have been associated with insulin resistance. A higher concentration of plasma SePP was found in people with type 2 diabetes and in 97 rodent models of type 2 diabetes, hepatic mRNA of SEPP1 was elevated [16]. In addition, treatment of mice with two intraperitoneal injections of $1 \mathrm{mg} / \mathrm{kg}$ body weight of purified human SePP induced glucose intolerance and insulin resistance [17]. Se and

100 selenoprotein levels have been related to lipid and carbohydrate metabolism [18] and 101 also to diabetes risk, where patients with type 2 diabetes have higher plasma concentrations of SePP [16]. Moreover, plasma SePP was positively associated with carotid intima media thickness [16]. In animal studies, Se supplementation either with 
104 selenite or selenate decreased plasma triglyceride levels, however, only selenate

105 decreased plasma cholesterol and suppressed the gene expression of gluconeogenic 106 enzymes in the liver. It is noteworthy that high levels of selenate were necessary to

107 achieve these effects; therefore, its use in clinical practice is not applicable [18].

108 SePP is encoded by the gene SEPP1 located in chromosome 5p12. It has two

109 functional single nucleotide polymorphisms (SNPs) [19, 20]. Both are a $G$ to A

110 substitution, the first one is located in the coding region of the gene changing the amino

111 acid Alanine to Threonine at position 234 of the protein (rs3877899). This

112 polymorphism modulates plasma Se levels in healthy adults in response to

113 supplementation with sodium selenite [20]. The second one (rs7579) is located in the

114 3’UTR, important for Sec insertion, and it modulates plasma SePP concentrations [20].

115 Genetic variants in SEPP1 have not been previously associated with lipid profile or 116 glucose levels in response to supplementation with Brazil nuts. Therefore, due to the

117 evidence associating SePP with glucose and lipid metabolism, the hypothesis of this

118 study was that functional polymorphisms in selenoprotein genes would influence the

119 response of serum lipids and glucose after supplementation with a high-Se and high-

120 lipid nut such as the Brazil nut.

\section{Methods}

\section{Study population and supplementation protocol}

123 One hundred and thirty unrelated healthy adults (males and females) aged 20 to

12460 years old were selected at University of São Paulo, Brazil. Volunteers taking

125 multivitamins and mineral supplements, anti-inflammatory drugs, with excessive

126 alcohol consumption, athletes, obese (BMI > 30) and with chronic diseases such as

127 cancer, diabetes and cardiovascular disease were not included in the study. The 
128 participants were invited by electronic correspondence and personal communication 129 when the protocol was explained.

130 The Supplementation with Brazil Nuts study (SU.BRA.NUT study) was an 131 eight-week dietary intervention with one Brazil nut a day in healthy subjects, followed 132 by eight more weeks without intervention. At the beginning of the study, $20 \mathrm{~mL}$ of

133 blood sample were drawn and subsequently the volunteers took a daily supplement of 134 one Brazil nut for eight weeks. At the end of four and eight weeks of supplementation, 135 another $20 \mathrm{~mL}$ blood sample was taken, and then two more blood samples were taken at 136 four week intervals during eight weeks without intervention. (Figure 1). Volunteers 137 were asked to complete a control calendar and mark with an " $x$ " when they consumed 138 each nut throughout the intervention period. For all participants, weight and height were 139 measured and the body mass index (BMI) was calculated. Written informed consent 140 was signed by all volunteers before blood sampling. The protocol was approved by 141 Faculty of Pharmaceutical Sciences Ethical Committee (CAE: 00961112.3.0000.0067)

142 and was conducted according to the Declaration of Helsinki.

\section{Centesimal Composition and Se content of Brazil nuts}

The centesimal composition of a random sample of Brazil nuts representative of

145 the four batches used in the study was analysed according to the methods proposed by 146 the Association of Official Analytical Chemists (AOAC, 1990). The Se content of 147 Brazil nuts was determined using hydrid generation flame atomic absorption 148 spectrometry (HGFAAS), as described previously [8].

\section{Blood sampling}

Fasting blood samples $(20 \mathrm{~mL})$ were drawn by venipuncture into four 5 -mL 
152 and subsequent genotyping. Another $5 \mathrm{~mL}$ of blood were collected in a tube without

153 anticoagulant to obtain serum. Plasma was separated by centrifugation at 3,000 rpm for

$15415 \mathrm{~min}$ at $4{ }^{\circ} \mathrm{C}$. The erythrocyte pellet was washed three times with $5 \mathrm{~mL}$ sterile $9 \mathrm{~g} / \mathrm{L}$

$155 \mathrm{NaCl}$ solution, slowly mixed by inversion, and centrifuged at 10,000 rpm for $10 \mathrm{~min}$

156 (Eppendorf, C5408) at $4{ }^{\circ} \mathrm{C}$, and the supernatant fluid was discarded. Aliquots of whole

157 blood, serum, plasma and erythrocytes were frozen at $-80{ }^{\circ} \mathrm{C}$ in sterile, demineralized

158 tubes until the analyses were performed.

\section{Biochemical parameters}

160

Concentrations of glucose, C-reactive protein and lipid profile (total cholesterol

161 (TC), HDL-c, LDL-c and triglycerides) in fasting serum were measured spectrometrically using commercial kits (Labtest, Minas Gerais, Brazil) adapted to a biochemical analyser (LabMax 240, Labtest, Minas Gerais, Brazil). Malondialdehyde

164 (MDA) was measured in plasma by high performance liquid chromatography (HPLC) on a Shimadzu (Kyoto, Japan) instrument with a Phenomenex (Torrance, CA, USA) reverse phase C18 column. The instrument was calibrated with a MDA standard stock solution in the following concentrations: $0.0,0.25,0.5,1.0,2.0,4.0,6.0$ and $12.0 \mu \mathrm{M}$.

\section{Genotyping}

Total DNA was extracted from $200 \mu \mathrm{L}$ of whole blood using the Purelink

170 Genomic DNA Minikit (Invitrogen, Life Technologies, California, USA). The final concentration was measured by using a NanoDrop ND 1000 spectrophotometer

172 (Thermo Fisher Scientific, Wilmington, DE, USA) and adjusted for further analysis.

173 SNPs in selenoprotein genes were determined by real-time PCR using Taqman SNP

174 Genotyping Assays (Thermo Fisher Scientific, Wilmington, DE, USA). Samples were

175 assayed along with no-template and internal controls for each genotype and run in the 
176 StepOne Plus Real Time PCR system under the following conditions: enzyme activation

177 at $95{ }^{\circ} \mathrm{C}$ for $10 \mathrm{~min}$, followed by 40 cycles at $92{ }^{\circ} \mathrm{C}$ for $15 \mathrm{~s}$ and $60{ }^{\circ} \mathrm{C}$ for $1 \mathrm{~min}$ for

178 annealing and extension. The allelic discrimination was obtained by performing an

179 endpoint read. The SNPs selected were in GPX1 gene (rs1050450), GPX4 gene

180 (rs713041), SEPP1 gene (rs3877899 and rs7579), SELS gene (rs34713741) and SEP15

181 gene (rs5845).

182 Statistical Analysis

183 Continuous variables were tested for normality using the Kolmogorov-Smirnov

184 test. The data were presented as geometric means (CI 95\%). Concentrations of blood

185 lipids, glucose and C-reactive protein were compared in the different time points using

186 ANOVA repeated measures or Friedman's test. For MDA, paired t Student test was

187 used. A genetic dominant model was used to assess differences in the presence of the

188 rare allele. In this model, individuals with the rare allele were combined in one

189 category, leaving the common genotype in another category. Multivariate linear

190 regression models were created using total cholesterol and glucose at each intervention

191 as dependent variables. Age, body fat composition, gender, tertiles of plasma Se, and

192 six SNPs were included as independent variables. Repeated measures analysis of

193 covariance (ANCOVA) was performed to investigate the effect of the genotypes for

194 SNPs appointed in the multivariate linear regression models. Covariates included for

195 outcome total cholesterol was age and for outcome glucose were gender, tertiles of

196 plasma Se and body fat composition. The Chi-square test with continuity correction was

197 used to determine whether genotype frequencies followed the Hardy-Weinberg

198 Equilibrium. The haplotype distribution and linkage disequilibrium were done in the

199 software Haploview 4.2. SNPs were considered in linkage disequilibrium when D’ was

$200>0.5$. Differences were considered significant at $p<0.05$. The analyses were performed 
201

202

203

204

205

206

using the Statistical Package for the Social Sciences software version 17.0 for Windows (SPSS, Chicago, IL, USA) and GraphPad Prism (GraphPad Prism version 5.00 for Windows, GraphPad Software, San Diego, CA, USA).

\section{Results}

\section{Demographic and anthropometric characteristics of the participants}

A total of 130 healthy volunteers completed the entire study protocol. Females constituted $75 \%$ of the group and $72 \%$ of the group self-reported as being Caucasian. Mean age for females was 28.4 y (95\% CI: 26.9 - 30.0) and for males was 29.2 y (95\% CI: 26.4 - 32.3). Family history of chronic diseases, such as cancer, diabetes mellitus and cardiovascular disease, was reported by $87 \%$ of the volunteers. At baseline, there was a difference between females and males for BMI (22.5 (95\% CI: 21.8 - 23.1) vs. 24.7 (95\% CI: 23.5 - 26.0), respectively $(p<0.001)$ and body fat percentage $(26.8$ (95\% CI: 25.6 - 28.0) vs. 21.4 (95\% CI: 19.0 - 24.1), respectively ( $p<0.001)$.

\section{Centesimal composition and Se content of Brazil nuts}

The Se content and centesimal composition of Brazil nuts are shown in Table 1. Four different batches were used during the supplementation. The mean \pm standard deviation for Se content of these four batches was $100.4 \pm 5.3 \mu \mathrm{g} / \mathrm{g}$. The average weight of the nuts was from 3 to 4 g, therefore each nut provided approximately $300 \mu \mathrm{g}$ of Se, which is approximately five times higher than the RDA for adults $(55 \mu \mathrm{g} / \mathrm{d})$.

\section{Lipid profile alterations after supplementation with Brazil nuts}

The lipid profile and MDA levels are reported in Table 2. During the intervention, fasting glucose concentrations decreased after four and eight weeks of 
224 daily consumption of Brazil nuts $(p<0.001)$. Total cholesterol concentrations also

225 decreased after eight weeks of supplementation. No significant differences were 226 observed for triglycerides, HDL-c, LDL-c and MDA levels. After interruption of Brazil

227 nut intake, fasting glucose concentrations at four and eight weeks were still lower than 228 baseline $(p<0.001)$. C-reactive protein levels at eight weeks after interruption were 229 higher than baseline $(p=0.023)$. No significant differences were observed for total 230 cholesterol, triglycerides, HDL-c, LDL-c and MDA levels.

\section{Influence of age on total cholesterol concentrations}

Multivariate linear regression models for total cholesterol were created in order the only variable associated with total cholesterol at 4 weeks of intervention, in which the increase of one year of age was related to the increase of $1.123 \mathrm{mg} / \mathrm{dL}$ of total cholesterol.

Body fat percentage, gender, plasma Se and rs3877899 on SEPP1 gene influence on glucose concentrations

The multivariate linear regression models created for glucose can be seen in Table 4. The body fat percentage was associated with glucose concentrations at three time points. An increase of one unit of body fat percentage increased 0.429, 0.495 and $0.583 \mathrm{mg} / \mathrm{dL}$ of glucose at baseline, four and eight weeks of intervention, respectively.

244 The presence of the SNP rs3877899 in SEPP1 gene was associated with glucose 245 concentrations at baseline, in which the presence of the variant allele A was related to a 246 reduction of $4.520 \mathrm{mg} / \mathrm{dL}$ of glucose $(p=0.025)$. The increase of plasma Se concentrations was related to an increase in glucose concentrations at 4 weeks of 
248 intervention $(p=0.046)$. Gender was associated with glucose concentrations at eight

249 weeks of intervention: being male was related to an increase of $8.145 \mathrm{mg} / \mathrm{dL}$ in glucose

250 concentrations $(p<0.001)$. The frequency of the genotypes and alleles for rs3877899 in

251 SEPP1 gene were GG 54\% ( $\mathrm{n}=70)$, GA 36\% $(\mathrm{n}=47)$ and AA 10\% $(\mathrm{n}=13)$ and for

252 rs7579 were GG 38\% ( $n=50)$, GA 42\% $(n=55)$ and AA 19\% $(n=25)$. Genotype

253 distribution did not significantly deviate from Hardy-Weinberg equilibrium for any of

254 the SNPs. Haplotype analysis showed evidence of linkage disequilibrium for the two

255 SNPs in the SEPP1 gene (rs7579, rs3877899) $\left(\mathrm{D}^{\prime}=1.0\right.$ and $\left.\mathrm{r}^{2}=0.15\right)$ with three

256 haplotypes observed: haplotype a (common) GG (44\%), haplotype b AG (28\%) and

257 haplotype GA (28\%).

258

259

Influence of SNPs in SEPP1 on serum cholesterol and glucose concentrations

260

Total cholesterol and glucose were stratified by SNPs in SEPP1 (Figure 2). The

261

SNP rs7579 modulated cholesterol response to supplementation. During the

intervention, total cholesterol decreased in both groups, but carriers of the rare allele A

had higher cholesterol concentrations during the supplementation, almost reaching

264 statistical significance after four weeks of intervention ( $p=0.054)$. Glucose

265 concentrations were modulated by the coding SNP rs3877899. During intervention,

266 glucose concentrations decreased significantly in both groups, however carriers of the

267 rare allele A had lower values at baseline $(p=0.004)$ and after eight weeks of

268 intervention $(p=0.013)$.

Discussion 
Previous studies have demonstrated that the intake of Brazil nuts improves blood

272 lipid profile in adults [8-10, 22]. The present results support and extend these 273 observations by showing that supplementation with one Brazil nut per day for eight 274 weeks decreases total serum cholesterol and glucose concentrations in healthy adults. In 275 addition, genetic variations in SEPP1 (rs3877899 and rs7579) modulated the effect of 276 Brazil nut supplementation on plasma glucose and total cholesterol levels. This study is 277 the first to observe an association between plasma cholesterol and glucose levels and the 278 polymorphisms in SEPP1 after Brazil nut supplementation.

The supplementation with one Brazil nut provided an average of $300 \mu \mathrm{g}$ of Se 280 for each nut. This is a high amount of Se and after a long term supplementation ( e.g., > 2811 year) could potentially increase the risk of metabolic diseases. Some epidemiological 282 studies have demonstrated that high plasma Se levels (above $150 \mu \mathrm{g} / \mathrm{L}$ ) increase the risk of all-cause mortality and cardiovascular disease. In the U.S. adult population with baseline plasma Se of $120 \mu \mathrm{g} / \mathrm{L}$, there is an increased risk of mortality for cancer mostly lung cancer - coronary and cardiovascular diseases [23]. The SELECT trial, designed to investigate the role of Se and vitamin E supplementation in prostate cancer 287 prevention, also observed an increased risk for diabetes after supplementation with $200 \mu \mathrm{g}$ of selenomethionine for 5 years. The population was fifty years old or older American males with high baseline Se status $(135 \mu \mathrm{g} / \mathrm{L})[24]$. Nevertheless, in our study the population had lower Se status at baseline $(90 \mu \mathrm{g} / \mathrm{L})$ and the duration of the intervention was only two months, which is much shorter than the duration of the SELECT trial. Moreover, our intervention was with one Brazil nut and not an isolated compound as the trial used and we are considering the genetic constitution of the

294 individuals, which the SELECT trial did not considered. All these differences could 
justify the absence of potential adverse effects of the Brazil nut supplementation in our 296 study.

Recent reports have demonstrated that the intake of Brazil nuts could increase HDL-c concentrations in obese females [8] and healthy adults [9], decrease total cholesterol and LDL-c in obese female adolescents [10] and decrease total cholesterol in dyslipidaemic adults [22]. In the present work, we found that the daily intake of one

301 Brazil nut for eight weeks decreased total cholesterol levels. Although the decrease in total cholesterol concentration can be considered of limited clinical application because these volunteers were not dyslipidaemic, this reduction after eight weeks of ingestion and the following increase after interruption of the intervention suggest that Brazil nuts may interfere with cholesterol metabolism and this might be relevant for populations at risk for metabolic syndrome or dyslipidaemia. Potential mechanisms underlying this improvement in blood lipid profile include the nutritional composition of Brazil nuts [25], the connection between Se metabolism with the mevalonate pathway [26] and with cholesterol biosynthesis [27]. Although

310 Brazil nuts have higher saturated fatty acids (SFA) concentrations compared to other nuts, the MUFA and PUFA contents are sufficient to exert their cholesterol lowering effect [4].

Another explanation for the decrease observed in total cholesterol concentration

314 is the relation between cholesterol and selenoprotein biosynthesis. The two metabolisms

315 are connected through the mevalonate pathway [26]. In order to be functional,

316 selenoproteins need to have the amino acid Sec inserted in their structure during 317 translation. This requires the synthesis and activation of the $\mathrm{tRNA}^{[\mathrm{Ser}] \mathrm{Sec}}$ which is 318 dependant on four bases modifications. One of these modifications is the 319 isopentenylation of adenosine 37, which requires isopentenyl pyrophosphate (IPP), a 
direct metabolite of mevalonate during cholesterol biosynthesis [26]. Our hypothesis is

321 that during the supplementation with a high Se content nut, the synthesis of 322 selenoproteins might be stimulated, which could be directing the IPP for the 323 isopentenylation of adenosine 37 of the $\mathrm{tRNA}^{[\mathrm{Ser}] \mathrm{Sec}}$, to the detriment of cholesterol 324 synthesis. Selenoproteins that are ranked high in the hierarchy of selenoprotein 325 expression, such as GPx4, could be preferentially synthesized under such conditions 326 [28]. The metabolism of Se and cholesterol are also connected via sterol response 327 element binding protein 2, SREBP2. Previously it was observed that Se supplementation increased expression of 15-deoxy-12,14-prostaglandin J2 [29], a ligand of the peroxisome proliferator-activated receptor- $\gamma$, PPAR- $\gamma$, which reduces SREBP2 decreasing cholesterol biosynthesis [30]. Moreover, studies in mice deleted for the Trsp 331 gene that encodes the specific transfer RNA for Sec, the $\mathrm{tRNA}^{[\mathrm{Ser}] \mathrm{Sec}}$, prevented selenoproteins expression and increased plasma cholesterol [31]. All these results indicate that one or more selenoproteins may be involved in the regulation of 334 cholesterol metabolism.

335 Experimental evidence has demonstrated that SNP rs3877899 in SEPP1 336 influences plasma Se concentration after supplementation with $200 \mu \mathrm{g} / \mathrm{d}$ of sodium 337 selenite for 4 weeks [20]. Our results extend these earlier observations, indicating that 338 individuals with the rare allele $\mathrm{A}(\mathrm{GA}+\mathrm{AA})$ had lower concentrations of glucose at 339 baseline and after eight weeks of supplementation with Brazil nuts in comparison to 340 subjects homozygous GG. As observed for total cholesterol, values were within the 341 range expected for healthy adults, limiting the clinical application of this result. 342 However, the reduction after just eight weeks and the maintenance of lower 343 concentrations after interruption of the intervention could be relevant as a higher 344 glucose lowering effect after Brazil nut intake should be expected for pre-diabetic or 
345 insulin-resistant individuals. Recently, a meta-analysis of randomized controlled trials

346 investigating the influence of nut consumption on glycaemic control in diabetes

347 demonstrated that diets with tree nuts per day significantly reduced fasting glucose

348 concentration in individuals with type 2 diabetes [32]. Furthermore, SePP has been

349 associated with the insulin metabolism in vitro and in vivo studies. SePP is expressed in

350 different tissues in mice [33] but it is mainly synthesised and secreted to the

351 bloodstream by the liver [34]. The pancreas of mice also expresses SePP in the $\alpha$-cells

352 which produces glucagon and in the $\beta$-cells which produces insulin [33]. SePP

353 expression was decreased in isolated islets after high glucose treatment [35]. Our

354 results indicate that after supplementation with Se the plasma SePP concentrations

355 increased (data not shown) and the glucose levels decreased, which is in accordance

356 with the previous findings observed in mice. The mechanism underlying this connection

357 of and glucose metabolism may be explained by the presence of a binding site for

358 FoxO1 transcription factor in the promoter gene of SEPP1 [35]. This transcription

359 factor regulates the expression of gluconeogenic enzymes, such as glucose-6-

360 phosphatase and phosphoenolpyruvate carboxykinase. These observations suggest that

361 SePP is an important factor regulating glucose metabolism. Therefore, the presence of

362 genetic polymorphisms in SEPP1 gene could modify how this selenoprotein regulates

363 the insulin metabolism.

364 In conclusion, this study indicates that supplementation with one Brazil nut per

365 day for eight weeks can reduce total plasma cholesterol concentration in healthy adults

366 and this response is apparently modulated by the coding SNP rs3877899 in SEPP1. In

367 addition, Brazil nut supplementation can also reduce fasting plasma glucose and this

368 effect is possibly modulated by rs7579 in SEPP1. Although the observed reductions were still within the normal range for clinical practice, these results may be important in 
370 future nutritional interventions with the goal of investigating the effect of

371 supplementation with Brazil nut on cholesterol and glucose metabolisms. Any future

372 Brazil nut supplementation study conducted for long term periods should be carried so

373 as to produce a more modest increase in plasma Se levels in order to achieve

374 concentrations not higher than $200 \mu \mathrm{g} / \mathrm{L}$, with the aim of avoiding adverse effects

375

376

377

378

379

380

381

382

383

384

385

386

387

388

389

390

391

392

393

394

395

396

397

398

399

400

401

402

403 observed in previous studies. These future studies should consider the baseline nutritional status, the gender and the genetic background of the participants.

\section{Conflict of interest}

There are no actual or potential conflicts of interest that might influence judgment on the part of any author.

\section{References}

1. Sabaté J, Ang Y (2009) Nuts and health outcomes: new epidemiologic evidence. Am J Clin Nutr 89:1643S-1648S. doi: 10.3945/ajcn.2009.26736Q.Am

2. Jiang R, Jacobs DR, Mayer-Davis E, et al. (2006) Nut and seed consumption and inflammatory markers in the Multi-Ethnic Study of Atherosclerosis. Am J Epidemiol 163:222-231. doi: 10.1093/aje/kwj033

3. O’Neil CE, Fulgoni VL, Nicklas TA (2015) Tree Nut consumption is associated with better adiposity measures and cardiovascular and metabolic syndrome health risk factors in U.S. adults: NHANES 2005-2010. Nutr J 14:64-71. doi: 10.1080/07315724.2011.10719996

4. Mukuddem-Petersen J, Oosthuizen W, Jerling JC (2005) A systematic review of the effects of nuts on blood lipid profiles in humans. J Nutr 135:2082-2089.

5. Welna M, Klimpel M, Zyrnicki W (2008) Investigation of major and trace elements and their distributions between lipid and non-lipid fractions in Brazil nuts by inductively coupled plasma atomic optical spectrometry. Food Chem 111:10121015. doi: 10.1016/j.foodchem.2008.04.067

6. Segura R, Javierre C, Lizarraga MA, Ros E (2006) Other relevant components of nuts: phytosterols, folate and minerals. Br J Nutr 96 Suppl 2:S36-S44. doi: 10.1017/BJN20061862

7. Bao Y, Han J, Hu FB, et al. (2013) Association of nut consumption with total and cause-specific mortality. N Engl J Med 369:2001-11. doi:

10.1056/NEJMoa1307352 
8. Cominetti C, de Bortoli MC, Garrido AB, Cozzolino SMF (2012) Brazilian nut consumption improves selenium status and glutathione peroxidase activity and reduces atherogenic risk in obese women. Nutr Res 32:403-7. doi: 10.1016/j.nutres.2012.05.005

9. Colpo E, Vilanova CDDA, Brenner Reetz LG, et al. (2013) A single consumption of high amounts of the Brazil nuts improves lipid profile of healthy volunteers. J Nutr Metab. doi: 10.1155/2013/653185

10. Maranhão P a, Kraemer-Aguiar LG, de Oliveira CL, et al. (2011) Brazil nuts intake improves lipid profile, oxidative stress and microvascular function in obese adolescents: a randomized controlled trial. Nutr Metab (Lond) 8:32. doi: 10.1186/1743-7075-8-32

11. Strunz CC, Oliveira T V., Vinagre JCM, et al. (2008) Brazil nut ingestion increased plasma selenium but had minimal effects on lipids, apolipoproteins, and highdensity lipoprotein function in human subjects. Nutr Res 28:151-155. doi: 10.1016/j.nutres.2008.01.004

12. Thomson CD, Chisholm A, Mclachlan SK, Campbell JM (2008) Brazil nuts : an effective way to improve selenium status. Am J Clin Nutr 87:379-384.

13. Rayman MP (2012) Selenium and human health. Lancet 379:1256-1268. doi: 10.1016/S0140-6736(11)61452-9

14. Hatfield DL, Gladyshev VN (2002) How Selenium Has Altered Our Understanding of the Genetic Code. Mol Cell Biol 22:3565-3576. doi: 10.1128/MCB.22.11.3565

15. Burk RF, Hill KE (2005) Selenoprotein P: an extracellular protein with unique physical characteristics and a role in selenium homeostasis. Annu Rev Nutr 25:215-235. doi: 10.1146/annurev.nutr.24.012003.132120

16. Yang SJ, Hwang SY, Choi HY, et al. (2011) Serum selenoprotein P levels in patients with type 2 diabetes and prediabetes: Implications for insulin resistance, inflammation, and atherosclerosis. J Clin Endocrinol Metab 96:1325-1329. doi: 10.1210/jc.2011-0620

17. Misu H, Takamura T, Takayama H, et al. (2010) A liver-derived secretory protein, selenoprotein P, causes insulin resistance. Cell Metab 12:483-495. doi: 10.1016/j.cmet.2010.09.015

18. Steinbrenner H (2013) Interference of selenium and selenoproteins with the insulinregulated carbohydrate and lipid metabolism. Free Radic Biol Med 65:1538-1547. doi: 10.1016/j.freeradbiomed.2013.07.016

19. Kryukov G V, Castellano S, Novoselov S V, et al. (2003) Characterization of mammalian selenoproteomes. Science 300:1439-1443. doi: 10.1126/science.1083516

20. Méplan C, Crosley LK, Nicol F, et al. (2007) Genetic polymorphisms in the human selenoprotein $\mathrm{P}$ gene determine the response of selenoprotein markers to selenium supplementation in a gender-specific manner (the SELGEN study). FASEB J 21:3063-3074. doi: 10.1096/fj.07-8166com

21. AOAC Association of Official Analytical Chemists (1990) Official methods of analysis, 15th ed. Washington

22. Carvalho RF, Huguenin GVB, Luiz RR, et al. (2015) Intake of partially defatted Brazil nut flour reduces serum cholesterol in hypercholesterolemic patients- a 
randomized controlled trial. Nutr J 14:59. doi: 10.1186/s12937-015-0036-X

450

451

452

453

454

455

456

457

458

459

460

461

462

463

464

465

466

467

468

469

470

471

472

473

474

475

476

477

478

479

480

481

482

483

484

485

486

487

488

489

490

23. Bleys J, Navas-Acien A, Guallar E (2008) Serum selenium levels and all-cause, cancer, and cardiovascular mortality among US adults. Arch Intern Med 168:404410. doi: 10.1001/archinternmed.2007.74

24. Hatfield DL, Gladyshev VN (2009) The Outcome of Selenium and Vitamin E Cancer Prevention Trial (SELECT) reveals the need for better understanding of selenium biology. Mol Interv 9:18-21. doi: 10.1124/mi.9.1.6

25. Ryan E, Galvin K, O’Connor TP, et al. (2006) Fatty acid profile, tocopherol, squalene and phytosterol content of brazil, pecan, pine, pistachio and cashew nuts. Int J Food Sci Nutr 57:219-228. doi: 10.1080/09637480600768077

26. Moosmann B, Behl C (2004) Selenoproteins, cholesterol-lowering drugs, and the consequences: revisiting of the mevalonate pathway. Trends Cardiovasc Med 14:273-81. doi: 10.1016/j.tcm.2004.08.003

27. Rayman MP, Stranges S, Griffin B a, et al. (2011) Effect of Supplementation With High-Selenium Yeast on Plasma Lipids. Ann Intern Med 154:656-665.

28. Schomburg L, Schweizer U (2009) Hierarchical regulation of selenoprotein expression and sex-specific effects of selenium. Biochim Biophys Acta 1790:1453-1462. doi: 10.1016/j.bbagen.2009.03.015

29. Vunta H, Davis F, Palempalli UD, et al. (2007) The anti-inflammatory effects of selenium are mediated through 15-deoxy-Delta12,14-prostaglandin J2 in macrophages. J Biol Chem 282:17964-17973. doi: 10.1074/jbc.M703075200

30. Klopotek A, Hirche F, Eder K (2006) PPAR gamma ligand troglitazone lowers cholesterol synthesis in HepG2 and Caco-2 cells via a reduced concentration of nuclear SREBP-2. Exp Biol Med 231:1365-1372.

31. Sengupta A, Carlson BA, Hoffman VJ, et al. (2008) Loss of housekeeping selenoprotein expression in mouse liver modulates lipoprotein metabolism. Biochem Biophys Res Commun 365:446-452. doi: 10.1038/jid.2014.371

32. Viguiliouk E, Kendall CWC, Blanco Mejia S, et al. (2014) Effect of Tree Nuts on Glycemic Control in Diabetes: A Systematic Review and Meta-Analysis of Randomized Controlled Dietary Trials. PLoS One 9:e103376. doi: 10.1371/journal.pone.0103376

33. Mao J, Teng W (2013) The relationship between selenoprotein P and glucose metabolism in experimental studies. Nutrients 5:1937-1948. doi: 10.3390/nu5061937

34. Burk RF, Hill KE (2009) Selenoprotein P-Expression, functions, and roles in mammals. Biochim Biophys Acta - Gen Subj 1790:1441-1447. doi: 10.1016/j.bbagen.2009.03.026

35. Steinbrenner H, Hotze AL, Speckmann B, et al. (2013) Localization and regulation of pancreatic selenoprotein P. J Mol Endocrinol 50:31-42. doi: 10.1530/JME-120105 
492 Table 1 Centesimal composition and selenium content in Brazil nuts used during the protocol

\begin{tabular}{ll}
\hline Nutrient & Mean \pm sd \\
\hline Energy (kcal) & $732.9 \pm 2.8$ \\
Carbohydrates (g) & $15.0 \pm 0.6$ \\
Proteins (g) & $13.1 \pm 0.2$ \\
Lipids (g) & $69.0 \pm 0.6$ \\
Ash (\%) & $3.1 \pm 0.9$ \\
Humidity (\%) & $4.7 \pm 0.7$ \\
Selenium $(\mu \mathrm{g} / \mathrm{g})$ & $100.4 \pm 5.3$ \\
\hline Values are mean \pm standard deviation for the four batches used.
\end{tabular}

493

494

495

496

497

Table 2 Biochemical parameters during and after diary intervention with one unit of Brazil nut for 8 weeks in healthy subjects.

\begin{tabular}{|c|c|c|c|c|}
\hline \multirow[t]{2}{*}{ Marker } & \multicolumn{3}{|c|}{ Diary intervention with 1 Brazil nut } & \multirow[b]{2}{*}{$P$ value } \\
\hline & baseline & 4 weeks & 8 weeks & \\
\hline Glucose (mg/dL) & $83.6(81.7-85.6)^{\mathrm{a}}$ & $81.0(79.2-82.9)^{\mathrm{b}}$ & $76.8(75.0-78.7)^{\mathrm{C}}$ & $<0.001$ \\
\hline Total cholesterol (mg/dL) & $191.3(184.5-198.4)^{\mathrm{a}}$ & $185.9(178.9-193.3)^{\mathrm{a}, \mathrm{b}}$ & $182.2(175.7-188.9)^{b}$ & 0.009 \\
\hline Triglycerides (mg/dL) & $87.2(80.2-94.7)$ & $88.7(81.7-96.3)$ & $88.7(81.9-96.1)$ & 0.431 \\
\hline HDL-c (mg/dL) & $55.5(52.9-58.2)$ & $55.6(53.2-58.1)$ & $55.2(52.6-58.0)$ & 0.756 \\
\hline LDL-c (mg/dL) & 104.5 (99.7-109.4) & $105.4(99.5-111.6)$ & $106.7(101.3-112.5)$ & 0.398 \\
\hline $\begin{array}{l}\text { C-Reactive Protein } \\
(\mathrm{mg} / \mathrm{dL})\end{array}$ & $1.04(0.85-1.28)$ & $1.10(0.89-1.37)$ & $1.22(0.99-1.51)$ & 0.641 \\
\hline $\mathrm{MDA}(\mathrm{mg} / \mathrm{dL})$ & $0.36(0.31-0.42)$ & na & $0.46(0.41-0.51)$ & 0.071 \\
\hline \multirow[t]{2}{*}{ Marker } & \multicolumn{3}{|c|}{ After interruption of intervention } & \\
\hline & baseline & 4 weeks & 8 weeks & $P$ value \\
\hline Glucose (mg/dL) & $83.6(81.7-85.6)^{\mathrm{a}}$ & $79.7(77.9-81.6)^{b}$ & $79.2(77.2-81.2)^{\mathrm{b}}$ & $<0.001$ \\
\hline Total cholesterol (mg/dL) & $191.3(184.5-198.4)$ & 186.5(179.1-194.3) & $190.4(182.9-198.3)$ & 0.729 \\
\hline Triglycerides (mg/dL) & $87.2(80.2-94.7)$ & $84.0(77.6-91.0)$ & $89.7(82.4-97.6)$ & 0.838 \\
\hline HDL-c (mg/dL) & $55.5(52.9-58.2)$ & $57.0(54.3-59.7)$ & $56.5(53.8-59.4)$ & 0.699 \\
\hline LDL-c (mg/dL) & $104.5(99.7-109.4)$ & $104.7(99.3-110.5)$ & $105.3(100.4-110.4)$ & 0.581 \\
\hline $\begin{array}{l}\text { C-reactive Protein } \\
(\mathrm{mg} / \mathrm{dL})\end{array}$ & $1.04(0.85-1.28)^{\mathrm{a}}$ & $1.07(0.86-1.34)^{\mathrm{a}, \mathrm{b}}$ & $1.32(1.08-1.61)^{b}$ & 0.023 \\
\hline
\end{tabular}

502

503

504

505

506 
508 Table 3 Multivariate linear regression models for dependent variable total cholesterol during intervention 509 with one unit of Brazil nut in healthy subjects

\begin{tabular}{|c|c|c|c|c|c|}
\hline Dependent variables & Independent variables & $\beta$ & St error & $\mathbf{R}^{2}$ & $P$ value \\
\hline $\begin{array}{l}\text { total cholesterol } \\
\text { at baseline }\end{array}$ & $\begin{array}{l}\text { gender } \\
\text { age } \\
\text { Plasma Se tertile } \\
\text { fat percentage } \\
\text { rs1050450 } \\
\text { rs713041 } \\
\text { rs3877899 } \\
\text { rs7579 } \\
\text { rs34713741 } \\
\text { rs5845 }\end{array}$ & $\begin{array}{l}-10.847 \\
0.831 \\
1.636 \\
0.127 \\
0.935 \\
-4.854 \\
1.768 \\
5.998 \\
-1.925 \\
0.511\end{array}$ & $\begin{array}{l}8.815 \\
0.456 \\
5.204 \\
0.626 \\
7.177 \\
7.190 \\
7.206 \\
7.432 \\
7.323 \\
7.187 \\
\end{array}$ & $\begin{array}{l}0.012 \\
0.027 \\
0.000 \\
0.000 \\
0.000 \\
0.003 \\
0.000 \\
0.005 \\
0.000 \\
0.000\end{array}$ & $\begin{array}{l}0.221 \\
0.071 \\
0.754 \\
0.840 \\
0.897 \\
0.501 \\
0.807 \\
0.421 \\
0.793 \\
0.943\end{array}$ \\
\hline $\begin{array}{l}\text { total cholesterol } \\
\text { at } 4 \text { weeks of } \\
\text { intervention }\end{array}$ & $\begin{array}{l}\text { gender } \\
\text { age } \\
\text { Plasma Se tertile } \\
\text { fat percentage } \\
\text { rs1050450 } \\
\text { rs713041 } \\
\text { rs3877899 } \\
\text { rs7579 } \\
\text { rs34713741 } \\
\text { rs5845 }\end{array}$ & $\begin{array}{l}-13.266 \\
1.123 \\
3.864 \\
-0.232 \\
-10.227 \\
-8.043 \\
3.385 \\
11.394 \\
2.664 \\
5.126\end{array}$ & $\begin{array}{l}9.392 \\
0.446 \\
6.178 \\
0.649 \\
7.143 \\
7.286 \\
7.259 \\
7.586 \\
7.442 \\
7.221\end{array}$ & $\begin{array}{l}0.016 \\
0.050 \\
0.003 \\
0.001 \\
0.016 \\
0.010 \\
0.001 \\
0.018 \\
0.001 \\
0.004\end{array}$ & $\begin{array}{l}0.160 \\
\mathbf{0 . 0 1 3} \\
0.532 \\
0.721 \\
0.155 \\
0.272 \\
0.642 \\
0.136 \\
0.721 \\
0.479\end{array}$ \\
\hline $\begin{array}{l}\text { total cholesterol } \\
\text { at } 8 \text { weeks of } \\
\text { intervention }\end{array}$ & $\begin{array}{l}\text { gender } \\
\text { age } \\
\text { Plasma Se tertile } \\
\text { fat percentage } \\
\text { rs1050450 } \\
\text { rs713041 } \\
\text { rs3877899 } \\
\text { rs7579 } \\
\text { rs34713741 } \\
\text { rs5845 }\end{array}$ & $\begin{array}{l}-5.118 \\
0.149 \\
-1.616 \\
-0.032 \\
-3.884 \\
0.019 \\
-2.998 \\
12.384 \\
8.449 \\
5.183\end{array}$ & $\begin{array}{l}9.407 \\
0.438 \\
5.113 \\
0.675 \\
6.897 \\
6.989 \\
6.995 \\
7.203 \\
7.189 \\
6.936\end{array}$ & $\begin{array}{l}0.003 \\
0.001 \\
0.001 \\
0.000 \\
0.003 \\
0.000 \\
0.001 \\
0.024 \\
0.010 \\
0.004\end{array}$ & $\begin{array}{l}0.587 \\
0.734 \\
0.753 \\
0.963 \\
0.574 \\
0.998 \\
0.669 \\
0.088 \\
0.242 \\
0.456\end{array}$ \\
\hline
\end{tabular}

510

511

512

513

514

515

516

517

518

519

520

521 
522 Table 4 Multivariate linear regression models for dependent variable glucose during intervention with 523 one unit of Brazil nut in healthy subjects

\begin{tabular}{|c|c|c|c|c|c|}
\hline Dependent variables & Independent variables & $\beta$ & St error & $\mathbf{R}^{2}$ & $P$ value \\
\hline $\begin{array}{l}\text { Glucose } \\
\text { at baseline }\end{array}$ & $\begin{array}{l}\text { gender } \\
\text { age } \\
\text { plasma Se tertile } \\
\text { fat percentage } \\
\text { rs1050450 } \\
\text { rs713041 } \\
\text { rs3877899 } \\
\text { rs7579 } \\
\text { rs34713741 } \\
\text { rs5845 }\end{array}$ & $\begin{array}{l}3.001 \\
0.019 \\
-0.783 \\
0.429 \\
0.973 \\
-1.771 \\
-4.520 \\
0.556 \\
-0.895 \\
-0.580\end{array}$ & $\begin{array}{l}2.431 \\
0.126 \\
1.435 \\
0.173 \\
1.979 \\
1.983 \\
1.987 \\
2.050 \\
2.020 \\
1.982\end{array}$ & $\begin{array}{l}0.012 \\
0.000 \\
0.002 \\
0.049 \\
0.002 \\
0.006 \\
0.041 \\
0.000 \\
0.001 \\
0.000\end{array}$ & $\begin{array}{l}0.219 \\
0.883 \\
0.586 \\
\mathbf{0 . 0 1 4} \\
0.624 \\
0.374 \\
\mathbf{0 . 0 2 5} \\
0.787 \\
0.658 \\
0.770\end{array}$ \\
\hline $\begin{array}{l}\text { Glucose } \\
\text { at 4weeks of } \\
\text { intervention }\end{array}$ & $\begin{array}{l}\text { gender } \\
\text { age } \\
\text { plasma Se tertile } \\
\text { fat percentage } \\
\text { rs1050450 } \\
\text { rs713041 } \\
\text { rs3877899 } \\
\text { rs7579 } \\
\text { rs34713741 } \\
\text { rs5845 }\end{array}$ & $\begin{array}{l}1.381 \\
-0.127 \\
3.128 \\
0.495 \\
-1.153 \\
-2.271 \\
-2.684 \\
-1.446 \\
1.124 \\
-2.142\end{array}$ & $\begin{array}{l}2.362 \\
0.112 \\
1.551 \\
0.163 \\
1.796 \\
1.833 \\
1.826 \\
1.908 \\
1.872 \\
1.816\end{array}$ & $\begin{array}{l}0.002 \\
0.010 \\
0.033 \\
0.071 \\
0.003 \\
0.012 \\
0.017 \\
0.004 \\
0.003 \\
0.011\end{array}$ & $\begin{array}{l}0.560 \\
0.259 \\
\mathbf{0 . 0 4 6} \\
\mathbf{0 . 0 0 3} \\
0.522 \\
0.218 \\
0.144 \\
0.450 \\
0.549 \\
0.241\end{array}$ \\
\hline $\begin{array}{l}\text { Glucose } \\
\text { at } 8 \text { weeks of } \\
\text { intervention }\end{array}$ & $\begin{array}{l}\text { gender } \\
\text { age } \\
\text { plasma Se tertile } \\
\text { fat percentage } \\
\text { rs1050450 } \\
\text { rs713041 } \\
\text { rs3877899 } \\
\text { rs7579 } \\
\text { rs34713741 } \\
\text { rs5845 }\end{array}$ & $\begin{array}{l}8.145 \\
-0.031 \\
1.499 \\
0.583 \\
-0.505 \\
-0.600 \\
-1.348 \\
-0.970 \\
-0.905 \\
-2.230 \\
\end{array}$ & $\begin{array}{l}2.475 \\
0.115 \\
1.345 \\
0.178 \\
1.814 \\
1.839 \\
1.840 \\
1.895 \\
1.891 \\
1.825 \\
\end{array}$ & $\begin{array}{l}0.083 \\
0.000 \\
0.010 \\
0.082 \\
0.000 \\
0.001 \\
0.004 \\
0.002 \\
0.002 \\
0.012 \\
\end{array}$ & $\begin{array}{l}\mathbf{0 . 0 0 1} \\
0.790 \\
0.267 \\
\mathbf{0 . 0 0 1} \\
0.781 \\
0.745 \\
0.465 \\
0.610 \\
0.633 \\
0.224 \\
\end{array}$ \\
\hline
\end{tabular}

524 


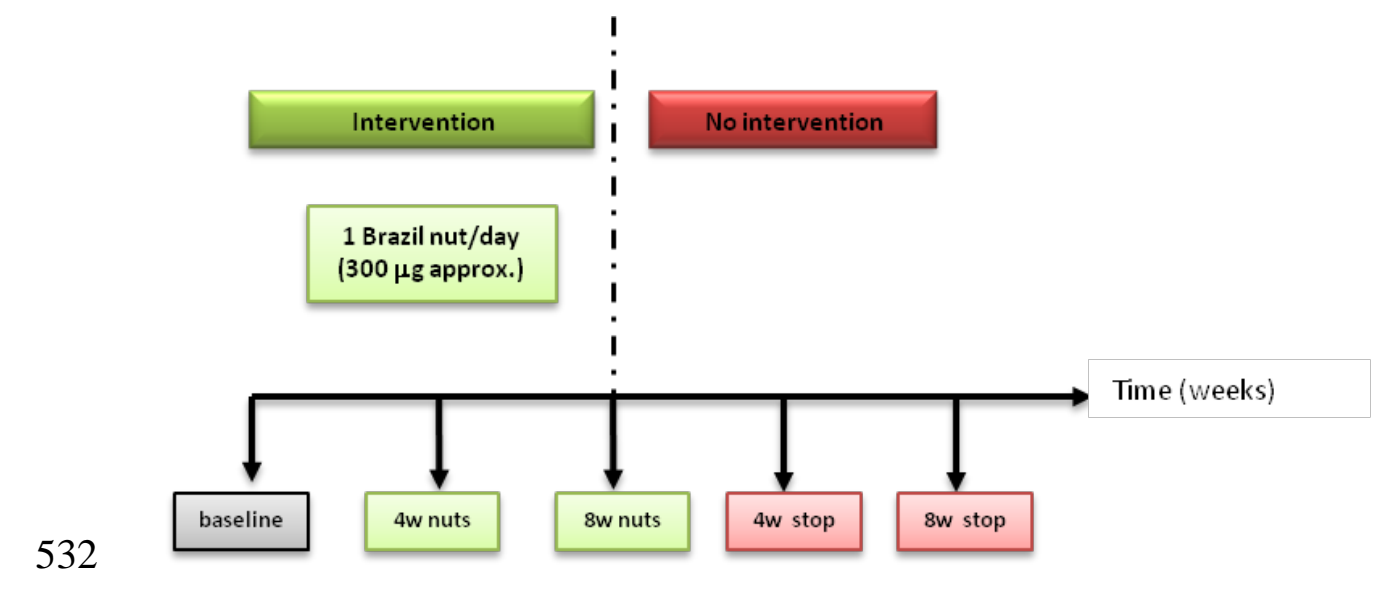

533 Fig. 1 Supplementation with Brazil nuts protocol.

534 Down arrows indicate blood sampling collection.
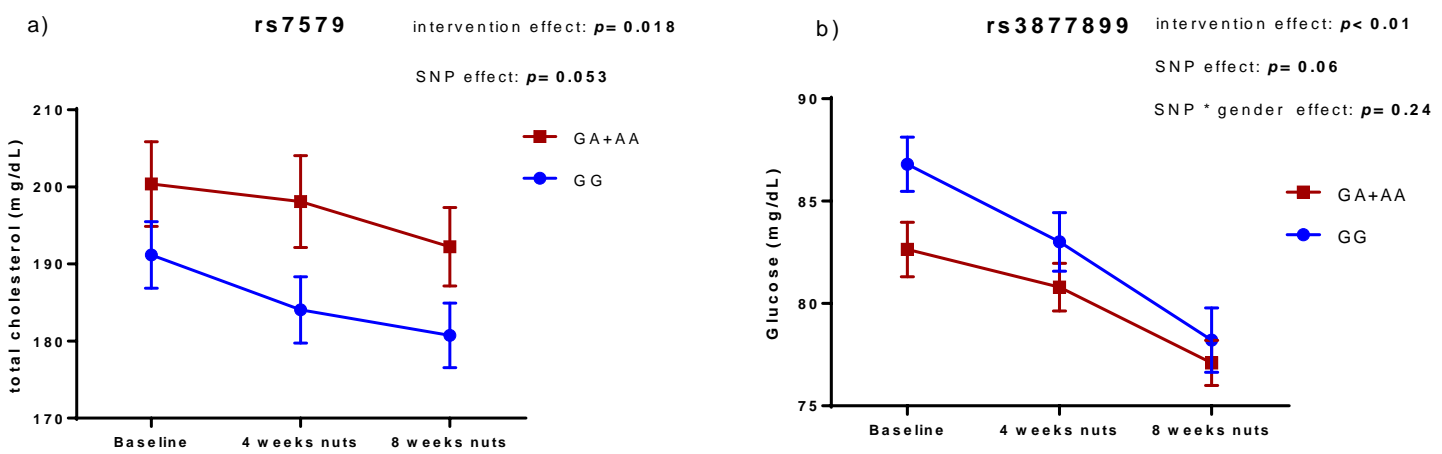

Fig. 2 Total cholesterol and glucose stratified by polymorphisms in SEPP1 gene

Values are means \pm st error. Two way ANCOVA repeated measures adjusted for multiple comparisons by Bonferroni test for total cholesterol (a) and glucose (b) levels. Covariates used: age for cholesterol and body fat composition, gender and plasma Se tertiles for glucose levels. 